\title{
Quantification of training and match-load distribution across a season in elite English Premier League soccer players
}

\begin{tabular}{|c|c|}
\hline Journal: & Science and Medicine in Football \\
\hline Manuscript ID & RSMF-2018-0122.R1 \\
\hline Manuscript Type: & Original Papers \\
\hline Keywords: & soccer training, mesocycle, microcycle, session RPE-TL, periodisation \\
\hline Abstract: & 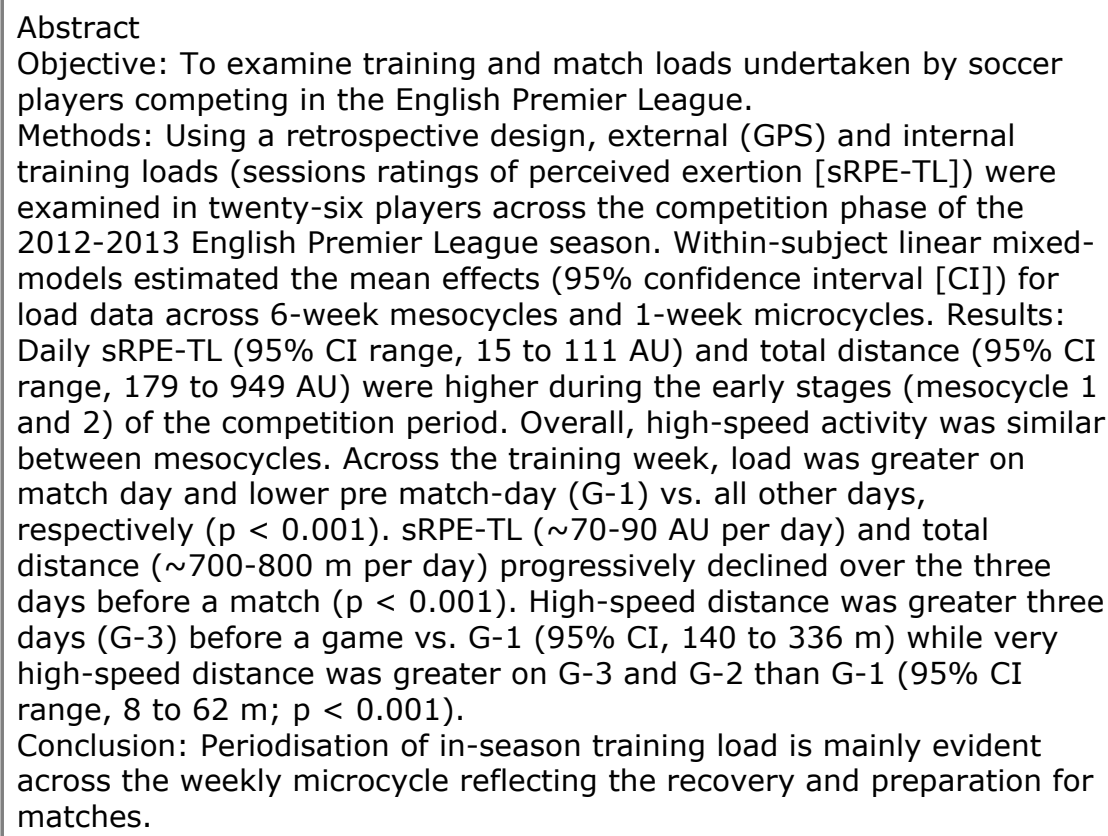 \\
\hline
\end{tabular}

\section{SCHOLARONE Manuscripts}


Quantification of training and match-load distribution across a season in elite English Premier League soccer players

Running Title: Seasonal training and match-load in elite soccer

Submission Type: Original Research

Keywords: soccer training, mesocycle, microcycle, session RPE-TL, periodisation 


\section{Abstract}

Objective: To examine_training and match loads undertaken by_soccer players competing in the English Premier League.

Methods: Using a retrospective design, external ( $\underline{\text { GPS }}$ ) and internal training loads (sessions ratings of perceived exertion [sRPE-TL]) were examined in twenty-six players across the competition phase of the 2012-2013 English Premier League season. Within-subject linear mixed-models estimated the mean effects $(95 \%$ confidence interval [CI]) for load data across 6-week mesocycles and 1-week microcycles. Results: Daily sRPE-TL (95\% CI range, 15 to 111 AU) and total distance (95\% CI range, 179 to 949 AU) were higher during the early stages (mesocycle 1 and 2 ) of the competition period. Overall, high-speed activity was $\underline{\text { similar between mesocycles. Across the training week, load was greater on match }}$ day and lower pre match-day (G-1) vs. all other days, respectively $(p<0.001)$. SRPE-TL ( 70-90 AU per day) and total distance $(\sim 700-800 \mathrm{~m}$ per day) progressively declined over the three days before a match $(p<0.001)$. High-speed distance was greater three days (G-3) before a game vs G-1 (95\% CI, 140 to $336 \mathrm{~m}$ ) while very high-speed distance was greater on G-3 and G-2 than G-1 (95\% CI range, $\underline{8 \text { to } 62 \mathrm{~m} ; p<0.001)}$.

Conclusion: Periodisation of in-season training load is mainly eviden $\underline{\text { weekly microcycle reflecting the recovery and preparation for matches. }}$

Keywords: soccer training, mesocycle, microcycle, sRPE-TL, periodisation 


\section{Introduction}

The complex physiological demands of soccer necessitate the implementation of training programmes which are multifactorial in nature (Morgans et al., 2014). Such requirements are further complicated by the stochastic movement profiles observed in elite soccer. The sporadic work bouts associated with soccer training may

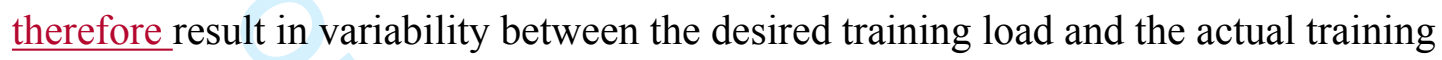
load the players are exposed to (Malone et al., 2015). Monitoring the individual player's daily training load therefore represents an important component of the effective planning of a soccer-specific training regimen (Weston, 2018).

The volume and intensity of training, collectively referred to as the training load (Impellizzeri et al., 2005), requires manipulation (periodisation) to elicit an optimum training stimulus (Malone et al., 2015). Many clubs therefore employ practitioners to collect, interpret and feedback information to coaches regarding the players daily load and status (Arkenhead and Nassis, 2016; Weston, 2018). To date, studies focused on training load quantification in soccer have largely focused on isolated training drills (Coutts et al., 2009; Casamichana and Castellano, 2010; Buchheit et al., 2015) or mesocyles of up to 10 weeks (Impellizzeri et al., 2004; Gaudino et al., 2013; Scott et al., 2013; Clemente et al., 2019). In contrast, while a plethora of studies have documented the long-term (season long) periodisation models adopted in other football codes (Gabbett and Jenkins, 2011; Moreira et al., 2016; McGahan et al., 2017), little data currently exists in elite soccer. 
Recent studies have provided some insight into the seasonal training load by players competing in the reserve league (Los Arcos et al., 2017; Martin-Garcia et al., 2018), Dutch Eredivisie League (Stevens et al., 2017), and the English Premier League (Malone et al., 2015; Anderson et al., 2016). variation in training load between (6-8 week training blocks)_(Malone et al., 2015; Anderson et al., 2016).Within weekly microcyles, load was also generally similar between training days with the exception of a marked reduction in load on the day preceding the game (Malone et al., 2015; Martin-Garcia et al., 2018). Whilst these studies provide valuable insights into the training loads experienced by elite players, further observations are required in order to gain a comprehensive insight into the collective periodisation practices adopted by professional teams (Weston, 2018).

nature of the

internal training load, or the individual physiological response to the external load administered by the $\operatorname{coach}_{2}$ represents the stimulus for training induced adaptation (Viru and Viru, 2000). Valid and reliable indicators of internal training load are therefore essential training process. Session RPE-TL (sRPETL) a valid indicator of the global internal training load during intermittent team sports such as soccer (Impellizzeri et al., 2004; Casamichana et al., 2013; Kelly et al., 2016). Despite the importance of the internal load in indicating the training response, observations on elite players have also been largely restricted to descriptions of short-term periods of training (Campos-Vazquez et al., 2015) with only one research group to date reporting session RPE-TL responses to long-term periods of training in elite players (Malone et al., 2015). 
Most of what is currently known about load monitoring derives from personal experiences or remains unpublished, since many elite teams are often unwilling to publish their data in order to retain competitive advantage. The training approaches adopted by elite teams and the degree to which these approaches incorporate periodisation strategies therefore remains largely unexplored in the literature. A recent survey of practitioners and coaches working in elite English soccer perceived that coaches were mostly responsible, and sports scientists/fitness coaches somewhat responsible, for planning training (Weston, 2018). Coaching practice is heavily influenced by tradition, emulation and historical precedence rather than through critical consideration of the latest research (Stoszkowski and Collins, 2016). Given the diverse coaching philosophies inherent in the modern elite game, further studies are needed to enhance our understanding as to how training loads in soccer are programmed across the annual cycle. The aim of the current investigation therefore was to quantify the combined external and internal training and match-load distribution across the competition phase of one full season at an English Premier League club.

\section{Methods}

\section{Participants}

Twenty-six elite-level soccer players were monitored across a 36-week competition phase of the 2012-2013 English Premier League (League Champions) season (mean $\pm \mathrm{SD}$ : age $27 \pm 5.4$ years, body mass $77 \pm 6.6 \mathrm{~kg}$, height $181 \pm 7.0 \mathrm{~cm})$. Players were assigned to one of five positional groups: central defender $(\mathrm{CD})(n=4)$, wide defender (WD) $(n=4)$, central midfielder $(\mathrm{CM})(n=7)$, wide midfielder (WM) $(n=$ 
$3)$, and attacker (A) $(n=8)$. The team competed in four official competitions throughout the season corresponding to 49 competitive matches in total. All of the players were notified as to the aim of the study, requirements, research procedures, benefits and risks before giving written informed consent. The Ethics committee of the relevant School at Liverpool John Moores University approved the study.

\section{Design}

For the purpose of the current study, all of the first team field-based training sessions carried out were considered for the analysis. This was inclusive of sessions involving both the starting line-up and non-starting players. Individual training, rehabilitation, recovery and specific fitness sessions were excluded from the analysis. Goalkeepers were not included in the study. Daily training load data was collected using the sRPE-TL method and micro-technology. Training and match data collection was carried out at the soccer club's training ground on the same natural outdoor grass training pitches, and at both home and away grounds in the English Premier League, respectively. A stadium-based tracking system was used to record match-play activities. All training and match load data observed during a 36-week competition phase of the season were categorised into 6-week mesocycle phases, and subsequent weekly calendar blocks (Sunday to Sunday). This enabled a full season's analysis of both the training and match-play load (Figure 1).

Training and match load data were also analysed in relation to the proximity of the forthcoming competitive game (day type). Six-day types in total were identified and analysed in the current study (G-3, G-2, G-1, match day (MD), G+2, G+3). For example, one day before the game was classified as game day minus one (G-1), two 
days before was G-2 etc. whereby $\mathrm{G}+2$ and $\mathrm{G}+3$ were the second- and third-days post-match, respectively. The day immediately following a game (i.e. G+1) was not included in the analysis as this was classified as a recovery day which involved a reduced load non-weight bearing recovery strategy and was therefore not representative of a training day. During the season there were one, two, and three game weeks. A one-game week consisted of 6 training days leading into the game. The two-game week had 1 recovery day following the first game (e.g. G+1) and 4 $\underline{\text { training days leading into the next game. A three-game week had } 1 \text { recovery session }}$ and a training day (G-1) between the first and second game and the second and third $\underline{\text { respectively. In some instances during two and three game weeks, games were }}$ played in close proximity (e.g. Saturday and Tuesday), leaving only two days $\underline{\text { between fixtures. In this scenario, }}$ recovery session and a training day (G-1) was implemented between games.

\section{$* * * *$ Figure 1 near here $* * * *$}

\section{Methodology}

\section{Training Load Assessment}

Internal Training Load: Internal training load (sRPE-TL, arbitrary units, AU) was estimated for all players by multiplying total training or match session duration (min) with session ratings of perceived exertion (sRPE) (Foster et al., 2001). Player sRPE was collected in isolation where possible, to avoid the potential effects of peer pressure $\sim 20$-minutes after each training session or match. All the players were familiarised with the use of the RPE scale during the pre-season training phase. 
External Training Load: Team Training and Matches. The player's external training

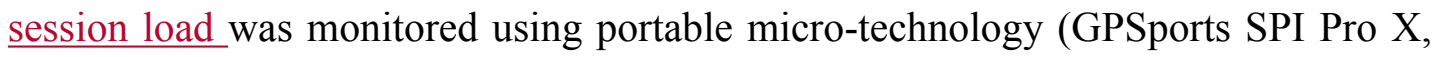
Canberra, Australia). The SPI Pro X (GPS and accelerometer integrated; size: 48x20x87mm; 76g) was placed inside a specially made vest, inside a mini pocket and positioned on the player's back, which was located centrally between the scapulae. The player wore micro-technology for the whole duration of the session. The unit was activated $\sim 15$ min before data collection to allow for the acquisition of satellite signals (Waldron et al., 2011). During every training session observation, the minimum acceptable number of available satellite signals was 8 , which is optimal for the measurement of human movement (Jennings et al., 2010). To avoid inter-unit error, each player wore the same micro-technology device for every training session observation (Jennings et al., 2010). The SPI Pro unit provides raw position, velocity and distance data at a rate of 15 samples-per-second $(15 \mathrm{~Hz})$. Every 3 raw data points were averaged for the purpose of the current study to provide a sampling frequency of $5 \mathrm{~Hz}$. This type of system has been shown to provide a reliable and valid estimate of the high-speed distance covered during multi-directional sports such as soccer (Portas et al., 2010; Randers et al., 2010; Varley et al., 2012; Waldron et al., 2011).

All training sessions and competitive matches during the 2012-13 season were observed and subsequently recorded. The mean number of training sessions completed, and the average match observations during each month $(n=5)$ are shown in Figure 2. Mean training session duration across all positions was $59 \pm 7 \mathrm{~min}$ (Figure 3). Matches were inclusive of domestic (Premier League, F.A. Cup, League Cup), and European (Champions League) fixtures. Friendly games were excluded 
from the analysis. A total of 49 matches were observed during the 36-week competition phase of the season. Individual player's activities were monitored during each game using a stadium-based multiple-camera match analysis system (Prozone Sports Limited, Leeds, UK). Data from both home and away fixtures were included. Only data from completed 90 min matches were used for the analysis. The median number of completed matches by individual players was 16 (range: 2-38). All Prozone data were processed using the appropriate software package (Prozone 3 Version 12.0.4.2., Prozone Sports Limited, Leeds, UK). This was carried out postgame(s) by the club's performance analyst and exported into a Microsoft Excel spreadsheet database (Microsoft Corporation, U.S.) for the analysis.

\section{$* * * *$ Figure 2 near here $* * * *$ \\ $* * * *$ Figure 3 near here $* * * *$}

The observed training and match-play activities (external load markers) identified for subsequent analysis were: total distance (m), distance (m) completed at high-speeds $>14.4 \mathrm{~km} / \mathrm{h}(\mathrm{m})$, and distance $(\mathrm{m})$ completed at very high-speeds $19.8-25.2 \mathrm{~km} / \mathrm{h}$. The current authors acknowledge that some differences in the measures derived from the micro-technology devices and Prozone system exist. In particular, it has been shown previously that high-intensity running distances are slightly-to-moderately greater when tracked using Prozone in comparison to GPSports devices (Buchheit et al., 2014). However, for the purpose of the current investigation, both the GPSports (training load), and Prozone (match load) data were combined together for the analysis (Anderson et al., 2016). 


\section{Statistical Analysis}

Data are represented as means \pm S.D. A multi-factorial linear mixed model was used to quantify mean differences between mesocycles, day-type and playing position. Use of linear mixed-modelling is suitable to examine repeated-measures data and unbalanced observations over time as, for example, in the context of our study where players differ in the number of training sessions and matches (Cnaan et al., 1997). Linear mixed modeling can also cope with the mixture of random and fixed level effects Cnaan et al., 1997) as well as with missing and 'nested' data (hierarchical models). The main effects for sub-group comparisons of each factor were summarised using least significance difference (LSD) multiple contrasts (Perneger, 1998).

Mean differences are presented with $95 \%$ confidence intervals $(\mathrm{Cl})$ as markers of uncertainty in the estimates. In the absence of an established anchor, despite the lack of real-world relevance of standardised effect sizes (Lenth, 2001), Cohen's d was reported as an additional statistic for interpreting the magnitude of the estimated effects (Cook et al., 2018). Effect size (ES), estimated from the ratio of the mean difference to the pooled standard deviation were also calculated. The ES magnitude was classified as trivial $(<0.2)$, small $(>0.2-0.6)$, moderate $(>0.6-1.2)$, large $(>1.2-$ 2.0) and very large (>2.0-4.0) (Hopkins et al., 2009). Within this particular context and to address the potential inflation of error rates associated with the large number of inferences in the present study, effects were declared meaningful if the point estimate for the mean difference expressed in standardised units attained threshold of moderate $(\mathrm{ES}>0.6)$. 


\section{Results \\ Mesocycle}

Total number of games mesocycle $1=6$; mesocycle $2=9$; mesocycle $3=10 ;$ mesocycle $4=6$; mesocycle 5 $=9$, and mesocycle $6=9$. Mean daily sRPE-TL, total distance, high-speed distance and very high-speed distance across each of the 6 x 6-week mesocycles by playing position are presented in Table 1. A statistically significant

mesocyle $($ all $p<0.001)$. aily sRPE-TL

greater in mesocycle 1 than all other mesocycles (95\% CI range, 16 to 111$)$ and greater values observed in mesocycle 2 than mesocyles 3 and 4 (95\% CI range, 15 to $91 \mathrm{AU})$. Total distance was higher in mesocycle 1 and 2 than mesocycles 3,4 , and 6 (95\% CI range, 179 to 949 AU). Meaningful differences in high-speed distance were only observed in mesocycle 5 compared to mesocycle $4(95 \%$ CI, 66 to $228 \mathrm{~m})$ with greater very highspeed distance observed in mesocycle 2 than mesocycle 4 (95\% CI, 21 to $64 \mathrm{~m})$. No statistically significant main effects of playing position or interaction between playing position and mesocycle were observed for any variable (all $p>$ $0.05)$.

\section{$* * * *$ Table 1 near here ${ }^{* * * *}$}

\section{Day Type}

Mean daily sRPE-TL, total distance, total high-speed distance and total very highspeed distance across all day types are represented in Figures 4-7. No statistically significant main effect of playing position were observed for any 
variable $(p>0.05)$. There was a statistically significant main effect of day-type for all variables (all $p<0.001$ ). Session RPE-TL (MD vs. other days: 95\% CI range, 208 to 409 AU; G-1 vs. other days: $95 \%$ CI range, -409 to $-47 \mathrm{AU}$ ), total distance (MD vs. other days: 95\% CI range, 4188 to $6069 \mathrm{~m}$; G-1 vs. other days: 95\% CI range, 6070 to $-430 \mathrm{~m}$ ), total high-speed distance (MD vs. Other days: 95\% CI range, 1466 to $1875 \mathrm{AU} ; \mathrm{G}-1$ vs. other days: 95\% CI range, -1875 to $-35 \mathrm{~m}$ ) and total very highspeed distance

days: 95\% CI range, -542 to $-20 \mathrm{~m}$ ) were higher on $\mathrm{MD}$ and lower on G-1 compared to all other days. SRPE-TL ( $70-90$ AU per day) and total distance ( $700-800 \mathrm{~m}$ per day) progressively reduced over the three days before a match $(p<0.001)$. Highspeed distance was greater on G-3 than G-1 (95\% CI, 140 to $336 \mathrm{~m})$ and very highspeed distance was greater on G-3 and G-2 vs G-1 (95\% CI range, 8 to $62 \mathrm{~m} ; p<$ $\underline{0.001 ; \text { Figure } 6 \text { and } 7) .}$

There was a statistically significant interaction between day-type and playing position for all variables predominantly reflecting positional differences on MD (all $p<0.001$; Figures 4-7). During training, RPE-TL was lower in WM than WD on G$3(95 \% \mathrm{CI},-208$ to $-18 \mathrm{AU})$. SRPE-TL was higher in A than WD and CM on (95\% CI range, $\underline{2} 9$ to $12 \underline{9}$ AU) and higher than all other positions on G-1 Attackers covered greater total distance than on CD and WD on $\mathrm{G}_{-1} 1(95 \% \mathrm{CI}$ range, 102 to $1387 \mathrm{~m})$. Differences in high-speed positions were only observed on MD. 


\section{$* * * *$ Figure 5 near here $* * * *$ \\ $* * * *$ Figure 6 near here $* * * *$}

$* * * *$ Figure 7 near here $* * * *$

\section{Discussion}

The aim of the current study was to examine the external and internal load incurred by elite soccer players across both the larger and smaller units of the annual competition period. Across the competition period there was limited variation in loading between the mesocycles with similar loads observed between playing positions. In contrast, marked fluctuations in external and internal load were evident within the weekly microcycle phase which was further influenced by playing position. This was generally characterised by a post-match recovery day (low load) followed by an increase in loading $(\mathrm{G}+2$ through to $\mathrm{G}+3$ and $\mathrm{G}-3)$ and subsequent taper through G-2, and G-1. The findings of the present study provide novel insights into the training periodisation undertaken by an elite English Premier League team during a championship winning season. Further studies of this type are required to enable a more comprehensive examination and subsequent development of the training methodologies adopted by elite coaches.

In the present study, total distance and sRPE-TL were $\sim 47 \underline{0 \mathrm{~m}}$ (95\% CI, 228 to 724

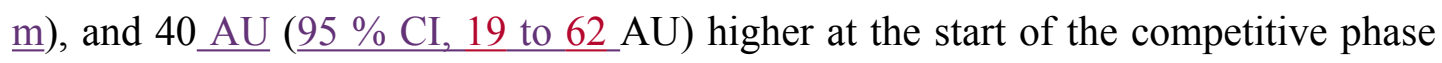
(mesocycle 1) versus the end (mesocycle 6). These changes in total distance are lower than those previously observed by Malone and colleagues (2015), where 
players covered $\sim 1300 \mathrm{~m}$ more total distance in mesocycle 1 than mesocycle 6 . Mean daily total distance (95\% CI, 472 to $947 \mathrm{~m}$ ), sRPE-TL (95\% CI, 67 to 111 $\mathrm{AU})$ and high-speed distance (95\% CI, -19 to $159 \mathrm{~m})$ were also $\simeq 700 \mathrm{~m}, 90 \mathrm{AU}$ and $\underline{70 \mathrm{~m}}$ higher respectively at the start of the season (mesocycle 1) compared with midseason (mesocycle 4) across all positions in the present study. Greater training loads at the beginning of the in-season competitive phase may often reflect the coaches' desire to maintain the emphasis on the development of fitness levels following the pre-season training period (Malone et al., 2015).

The middle phase of the season (mesocycle 4 - mid-December) is associated with the lead into the Christmas period, which typically has a highly congested fixture schedule in the English Premier League. We presently observed the highest number of matches $(n=7)$ and the greatest average number of training session observations 62 (range: [n], 40-62) during this period. However, the average training session duration (48 $\pm 5 \mathrm{~min}$ ) was greatly reduced across December compared to all other periods of the season which resulted in the lowest SRPE-TL, total distance, highspeed distance, and very high-speed distances. These changes were consistent with the strategy employed by the head coach which aimed to offset the increased frequency of matches by reducing training induced fatigue in order to maintain match readiness. Our findings are in-line with Malone and colleagues (2015) who also reported reductions in training volume during the mid-season phase, whereby sRPE-TL was lower by $\sim 80$ AU across this period.

Training load prescription in soccer is largely influenced by the competition frequency, with in-season microcycles of typically 3 to 7 days in duration repeatedly 
occurring around matches (Morgans et al., 2014; Malone et al., 2015; Akenhead et al., 2016).

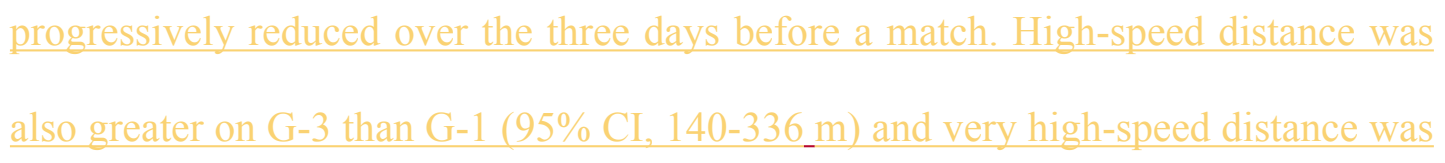

The higher training loads observed on G-3 reflected training sessions incorporating drills undertaken on larger pitch sizes (i.e. extensive endurance position-specific practices) with a greater number of players (7v $7-11 v$ 11). More intensive endurance drills were undertaken in smaller training areas with a reduced number of players (e.g. $3 v 2,5 v 4$, and $1 v 1-3 v 3$ ) as part of training sessions undertaken on G-2. The aim of these training sessions was to elicit intensities deemed suitable to produce the physiological adaptations required for soccer-specific endurance (Little and Williams, 2006) while simultaneously aiding the development of technical and tactical skills similar to situations experienced during the game. All variables were lowest on G-1 as a consequence of the implementation of lower intensity and shorter training sessions the day before a match, consisting mainly of activation and reactive speed training type drills. The decline in daily load from G-3 to G-1 in the current study is in agreement with recent observations in Spanish La Liga reserve team players who showed a marked reduction in total distance $(\sim 3000 \mathrm{~m})$ and high-speed distance $(\sim 170 \mathrm{~m})$ across the three-day period (Martin-Garcia et al., 2018). In contrast, Malone and colleagues (2015) reported greater high-speed distances on G-1 than G-2 in English Premier League players. The rationale for this approach was not reported by the authors, however, it would seem counterproductive and contrary to 'tapering' approaches previously discussed in the literature (Owen et al., 2017). Reducing training load on the day preceding a competitive match may enhance the capability of significantly 
decreasing physical stressors upon players, whilst leading to reductions in an accumulative fatigue response (Owen et al., 2017).

The present findings demonstrate that a gradual reduction in external and internal load across the three-day period leading into a game may constitute an important element of training periodisation adopted in the elite game. The 'three-day' prematch tapering strategy facilitates the gradual 'unloading' of players which will serve to increase player readiness for the game. It is acknowledged that this type of three-day load reduction approach does not concur with the traditional tapering strategies reported for individual sports, whereby training load is typically reduced over the course of 7 to 28 days pre-competition (Mujika et al., 2004). This may be a consequence of several factors. A congested and 'ever changing' fixture schedule restricts the amount of time available to fully prepare players, making a 'one-size global approach' to periodisation unfeasible within elite soccer. There is also the need for constant flexibility to allow for the management of playing times, demanding travel schedules, and individual player 'micro-management'.

Training and match load in the current study showed limited variation between playing positions across the season's six mesocycles. This likely reflected the inclusion of match data in the analysis which may have masked any potential differences in training load per se. Analysis of the loading patterns during the weekly microcycle training days in the present study provides a more precise comparison of positional loads. 
Attacking players also covered $\sim 600 \mathrm{~m}$ and $\sim 650 \mathrm{~m}$ more total distance compared to In contrast to the present observations, in English Premier League players, Malone et al. (2015) reported limited positional differences in the days leading into a game. In Spanish reserve team players, Martin-Garcia and colleagues (2018) reported the highest total distance in central and offensive midfielders during the three-day lead into competition whilst wide defenders covered the greatest high-speed running distance during the same period. Collectively, these positional differences likely reflect the diversity in training strategies adopted by different coaching teams which are often driven by the head coach (Akenhead and Nassis, 2016; Weston, 2018).

\section{Conclusions}

In summary, our study has systematically quantified the training and match loads employed by an English Premier League club during a championship winning season. Training load across the mesocycle periods showed limited variation and suggests that training schedules employed in elite soccer may be highly repetitive likely reflecting the nature of the competition demands. Periodisation of training load was evident within the weekly microcycle including the three-day period leading into competition. This reflected the coaching teams approach to match recovery and preparation across the long competitive period. Further research is needed to expand our understanding of the loads encountered by elite players and the different periodisation models adopted by coaching teams. 


\section{Practical Implications}

The present data centers on a championship winning season and extends the limited literature by providing novel insights into the training loads encountered by elite soccer players. The present findings provide coaches and practitioners with insights into a successful periodisation strategy that was adopted during weekly microcycles in an attempt to facilitate match recovery and preparation. Such strategies are likely to be important in the modern game due to the relatively constant loading incurred across the season as a consequence of the high frequency of matches encountered by elite teams. Methodological challenges inherent in soccer, limit the ability to determine the direct influence of training load on team match physical performance and/or success and therefore our understanding of what may constitute optimal periodisation of training. Future work could therefore focus on the analysis of training load encountered by the same players under different coaches and/or periodisation strategies across extended periods of time or between seasons. By examining both the variation in load as well as factors such as performance testing, player wellness and injury rates, such approaches could represent a move towards a better understanding of how to best prepare elite players.

\section{Disclosure statement}

No potential conflict of interest was reported by the authors. 


\title{
References
}

Akenhead, R., and Nassis, G. P. (2016). Training load and player monitoring in high-level football: current practice and perceptions. International Journal of Sports Physiology and Performance, 11 (5), 587-593.

\begin{abstract}
Akenhead, R., Harley, J., and Tweddle, S. (2016). Examining the external training load of an English Premier League football team with special reference to acceleration. Journal of Strength and Conditioning Research, 30 (9), 2424-2432.
\end{abstract}

Anderson, L., Orme, P., Di Michele, R., Close, G. L., Milsom, J., Morgans, R., Drust, B., and Morton, J. P. (2016). Quantification of seasonal long physical load in soccer players with different starting status from the English Premier League: implications for maintaining squad physical fitness. International Journal of Sports Physiology and Performance, 11 (8), 1038-1046.

Aoki, Marcelo. S., Ronda, Lorena T., Marcelino, Pablo R., Drago, Gustavo., Carling, Chris., Bradley, Paul S., and Moreira, Alexandre. (2017). Monitoring Training Loads in Professional Basketball Players Engaged in a Periodized Training Program. Journal of Strength and Conditioning Research, 31 (2), 348-358.

Buchheit, M., Manouvrier, C., Cassirame, J., and Morin, J. B. (2015). Monitoring Locomotor Load in Soccer: Is Metabolic Power, Powerful? International Journal of Sports Medicine, 36 (14), 1149-1155. 
Buchheit, M., Allen, A., Poon, T, K., Modonutti, M., Gregson, W., and Di Salvo, V. (2014). Integrating different tracking systems in football: multiple camera semiautomatic system, local position measurement and GPS technologies. Journal of Sports Sciences, 32 (20), 1844-1857.

Campos-Vazquez, M. A., Mendez-Villanueva , A., Gonzalez-Jurado , J. A., LeónPrados , J. A., and Santalla, A. (2015). Relationships Between Rating-of-PerceivedExertion- and Heart- Rate-Derived Internal Training Load in Professional Soccer Players: A Comparison of On-Field Integrated Training Sessions. International Journal of Sports Physiology and Performance, 10 (5), 587-592.

Casamichana, D., and Castellano, J. (2010). Time-motion, heart rate, perceptual and motor behaviour demands in small-sides soccer games: effects of pitch size. Journal of Sports Sciences, 28 (14), 1615-1623.

Casamichana, D., Castellano, J., Calleja, J., San Roman, J., and Castagna, C. (2013). Relationship between Indicators of Training Load in Soccer Players. Journal of Strength and Conditioning Research, 27 (2), 369-374.

Clemente, F. M., Owen, A., Serra-Olivares, J., Nikolaidis, P. T., van der Linden, C. M. I., and Mendes, B. (2019). Characterization of the weekly external load profile of professional soccer teams from Portugal and the Netherlands. Journal of Human Kinetics, 66, 155-164. 
Cnaan A, Laird NM, Slasor P. (1997). Using the general linear mixed model to analyse unbalanced repeated measures and longitudinal data. Stat Med. 16, 23492380 .

Cook, J.A., Julious, S.A, Sones, W., Hampson, L.V., Hewitt, C., Berlin, J.A, Ashby, D., Emsley, R., Fergusson, D.A. and Walters, S.J. (2018). DELTA 2guidance on choosing the target difference and undertaking and reporting the sample size calculation for a randomised controlled trial. British Medical Journal, 363: k3750_ $\underline{\mathrm{k} 3757 .}$.

Coutts, A. J., Rampinini, E., Marcora, S. M., Castagna, C., and Impellizzeri, F. M. (2009). Heart and blood lactate correlates of perceived exertion during small-sided soccer games. Journal of Science and Medicine in Sport, 12 (1), 79-84.

Ebben, W. P., Carroll, R. M., and Simenz, C. J. (2004). Strength and conditioning practices of National Hockey League strength and conditioning coaches. Journal of Strength and Conditioning Research, 18 (4), 889-897.

Ebben, W. P., Hintz, M. J., and Simenz, C. J. (2005). Strength and conditioning practices of Major League Baseball strength and conditioning coaches. Journal of Strength and Conditioning Research, 19 (3), 538-546.

Foster, C., Florhaug, J. A., Franklin, J., Gottschall, L., Hrovatin, L. A., Parker, S., Doleshal, P., and Dodge, C. (2001). A new approach to monitoring exercise training. Journal of Strength and Conditioning Research, 15 (1), 109-115. 
Gabbett, T. J., and Jenkins, D. G. (2011). Relationship between training load and injury in professional rugby league players. Journal of Science and Medicine in Sport, 14, 204-209.

Gaudino, P., Iaia, F. M., Alberti, G., Strudwick, A. J., Atkinson, G., and Gregson, W. (2013). Monitoring training in elite soccer players: systematic bias between running speed and metabolic power data. International Journal of Sports Medicine, 34 (11), 963-968.

Hopkins, W. G., Marshall, S. W., Batterham, A. M., and Hanin, J. (2009). Progressive Statistics for Studies in sports Medicine and Exercise Science. Medicine and Science in Sports and Exercise, 41 (1), 3-12.

Impellizzeri, F. M., Rampinini, E., Coutts, A. J., Sassi, A. and Marcora, S. M. (2004). Use of RPE-Based Training Load in Soccer. Medicine and Science in Sports and Exercise, 36 (6), 1042-1047.

Impellizzeri, F. M., Rampinini, E., Marcora, S. M. (2005). Physiological assessment of aerobic training in soccer. Journal of Sports Sciences, 23, 583-592.

Jennings, D., Cormack, S., Coutts, A. J., Boyd, L. J., and Aughey, R. J. (2010). Variability of GPS units for measuring distance in team sport movements. International Journal of Sports Physiology and Performance. 5, 565-569. 
Kelly, D. M., Strudwick, A. J., Atkinson, G., Drust, B., and Gregson, W. (2016). The within-participant correlation between perception of effort and heart rate-based estimations of training load in elite soccer players. Journal of Sports Sciences, 34 (14), 1328-1332.

Lenth, R.V. (2006). Some practical guidelines for effective sample size. The American Statistician, 55 (3), 187-193.

Little, T., and Williams, A. G. (2006). Suitability of soccer Training Drills for Endurance Training. Journal of Strength and Conditioning Research, 20 (2), 316319.

Malone, J. J., Rocco, D, M., Morgans, R., Burgess, D., Morton, J, P., and Drust, B. (2015). Seasonal Training-Load Quantification in Elite English Premier League Soccer Players, International Journal of Sports Physiology and Performance, 10, 489-497.

Martin-Garcia, A., Gomez Diaz, A., Bradley, P. S., Morera, F., and Casamichana, D. (2018). Quantification of a professional football team's external load using a microcycle structure. Journal of Strength and Conditioning Research, (In Press.).

McGahan, J., O’Neill, C., and Burns, C. (2017). Seasonal variation of training, competition load and markers of wellness in an elite Gaelic football team. Physical Therapy in Sport, 28, e24. 
Moreira, A., Bilsborough, J. C., Sullivan, C. J., Cianciosi, M., Aoki, M. S., and Coutts, A. J. (2016). Training Periodization of Professional Australian Football Players During an Entire Australian Football League Season. International Journal of Sports Physiology and Performance, 10, 566-571.

Morgans, R., Orme, P., Anderson, L., and Drust, B. (2014). Principles and practices of training for soccer. Journal of Sport and Health Science, 3 (4), 251-257.

Mujika, I., Padilla, S., Pyne, D., and Busso, T. (2004). Physiological changes associated with the pre-event taper in athletes. Sports Medicine, 34 (13), 891-927.

Owen, A. L., Lago-Penas, C., Miguel-Angel, G., Mendes, B., and Dellal, A. (2017). Analysis of a training mesocycle and positional quantification in elite European soccer players. International Journal of Sports Science \& Coaching, 12 (5), 665-676.

Perneger, T. V. (1998). Whats wrong with Bonferroni adjustments. British Medical Journal, 316, 1236-1238.

Portas, M. D., Harley, J. A., Barnes, C. A., and Rush, C. J. (2010). The validity and reliability of $1-\mathrm{Hz}$ and $5-\mathrm{Hz}$ global positioning systems for linear, multidirectional, and soccer-specific activities. International Journal of Sports Physiology and Performance, 5, 448-458. 
Randers, M. B., Mujika, I., Hewitt, A., Santisteban, J., Bischoff, R., Solano, R., Zubillaga, A., Peltola, E., Krustrup, P., and Mohr, M. (2010). Application of four different football match analysis systems: a comparative study. Journal of Sports Sciences. 28, 171-182.

Scott, B. R., Lockie, R. G., Knight, T. J., Clark, A. C., and Xanne, A. K. Janse de Jonge. (2013). A Comparison of Methods to Quantify the In-Season Training Load of Professional Soccer Players. International Journal of Sports Physiology and Performance, 8 (2), 195-202.

Stevens, T. G. A., de Ruiter, C. J., Twisk, J. W. R., Savelsbergh, G. J. P., and beek, P. J. (2017). Quantification of in-season training load relative to match load in professional Dutch Eredivisie football players. Science and Medicine in Football, 1 (2), 117-125.

Stoszkowski, J., and Collins, D. (2016). Sources, topics and use of knowledge by coaches. Journal of Sports Sciences, 34 (9), 794-802.

Varley, M. C., Fairweather, I. H., and Aughey, R. J. (2012). Validity and reliability of GPS for measuring instantaneous velocity during acceleration, deceleration, and constant motion. Journal of Sports Sciences. 30 (2), 121-127.

Viru, A. \& Viru, M., (2000). Nature of training effects. In W. E. Garett, D. T. Kirkundall (Eds.) Exercise and Sport Science (pp. 67-95). Philadelphia: Lippincott Williams and Wilkins. 
Waldron, M., Worsfold, P., Twist, C., and Lamb, K. (2011). Concurrent validity and test-retest reliability of a global positioning system (GPS) and timing gate to assess sprint performance variables. Journal of Sports Sciences, 29, 1613-1619.

Weston, M. (2018). Training load monitoring in elite English soccer: a comparison of practices and perceptions between coaches and practitioners. Science and Medicine in Football, 2 (3), 216-224. 

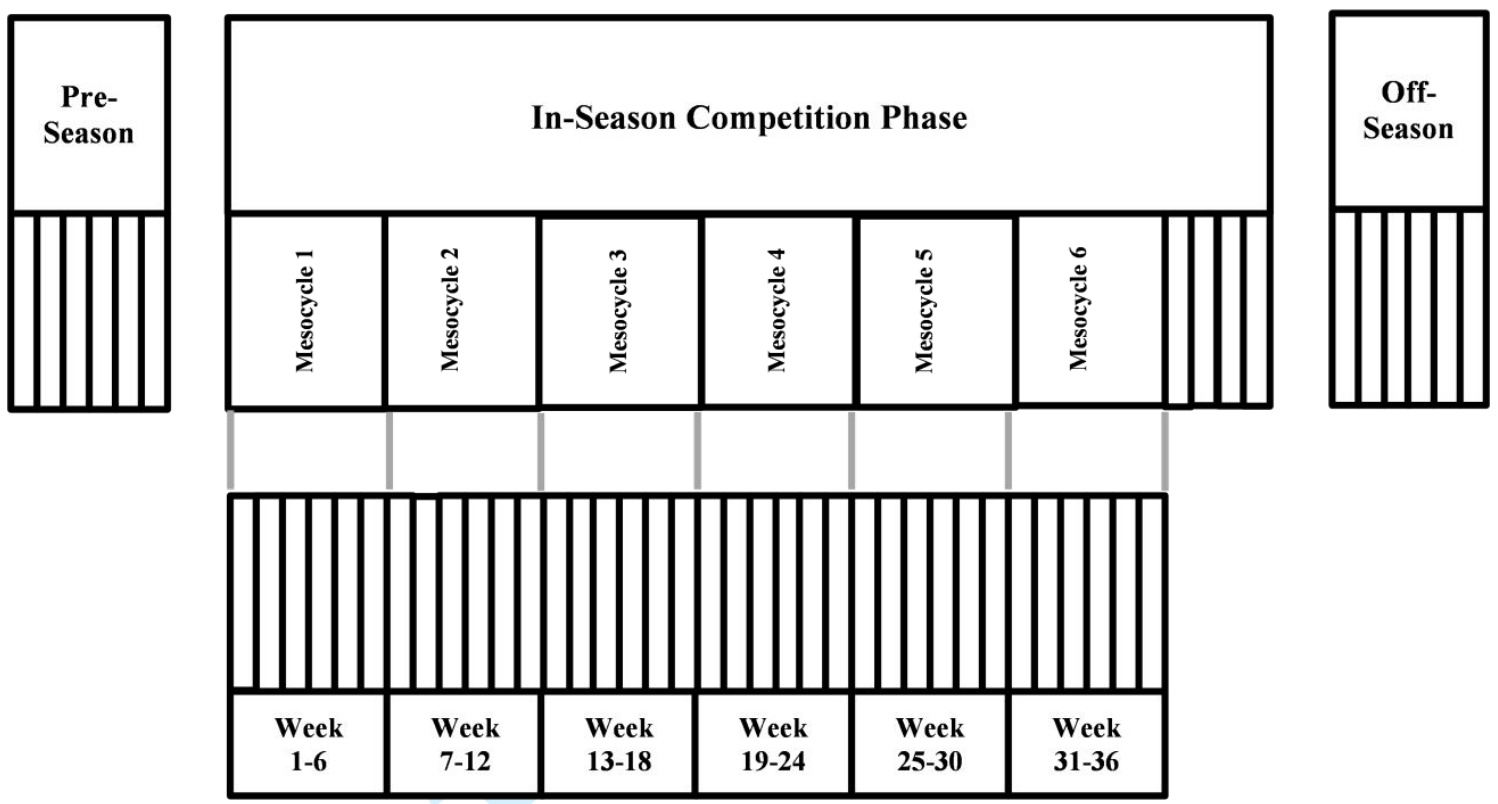

Figure 1. Diagrammatic representation of the experimental design used in the current study. Each small block represents individual weeks within the annual training cycle, with larger blocks showing the 6-week mesocycle phases of the competitive season. 
$\square C D \square W D \square C M \square W M \square A \bullet M a t c h e s$

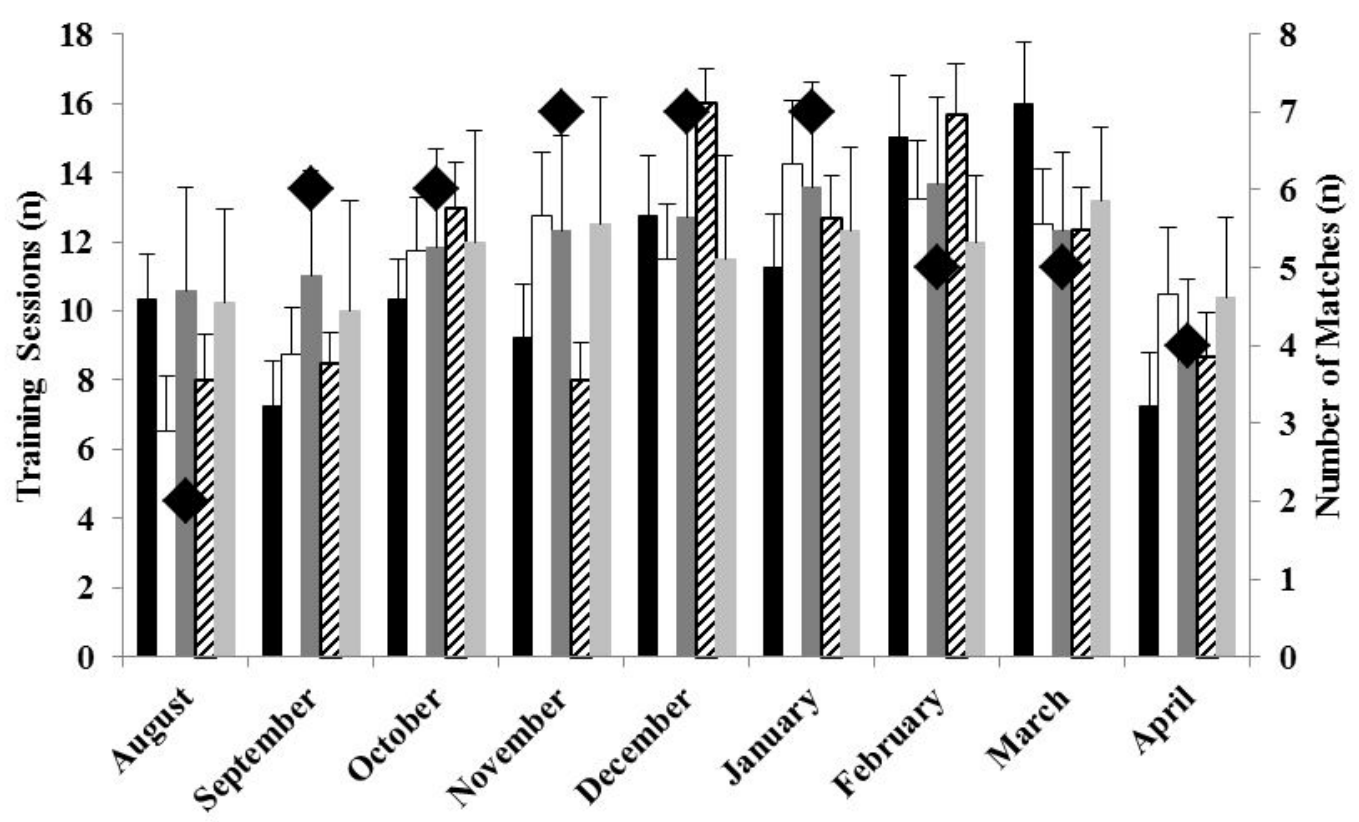

Figure 2. Mean $\pm \mathrm{SD}$ number of training sessions and competitive games by playing position during the 2012-13 season. 


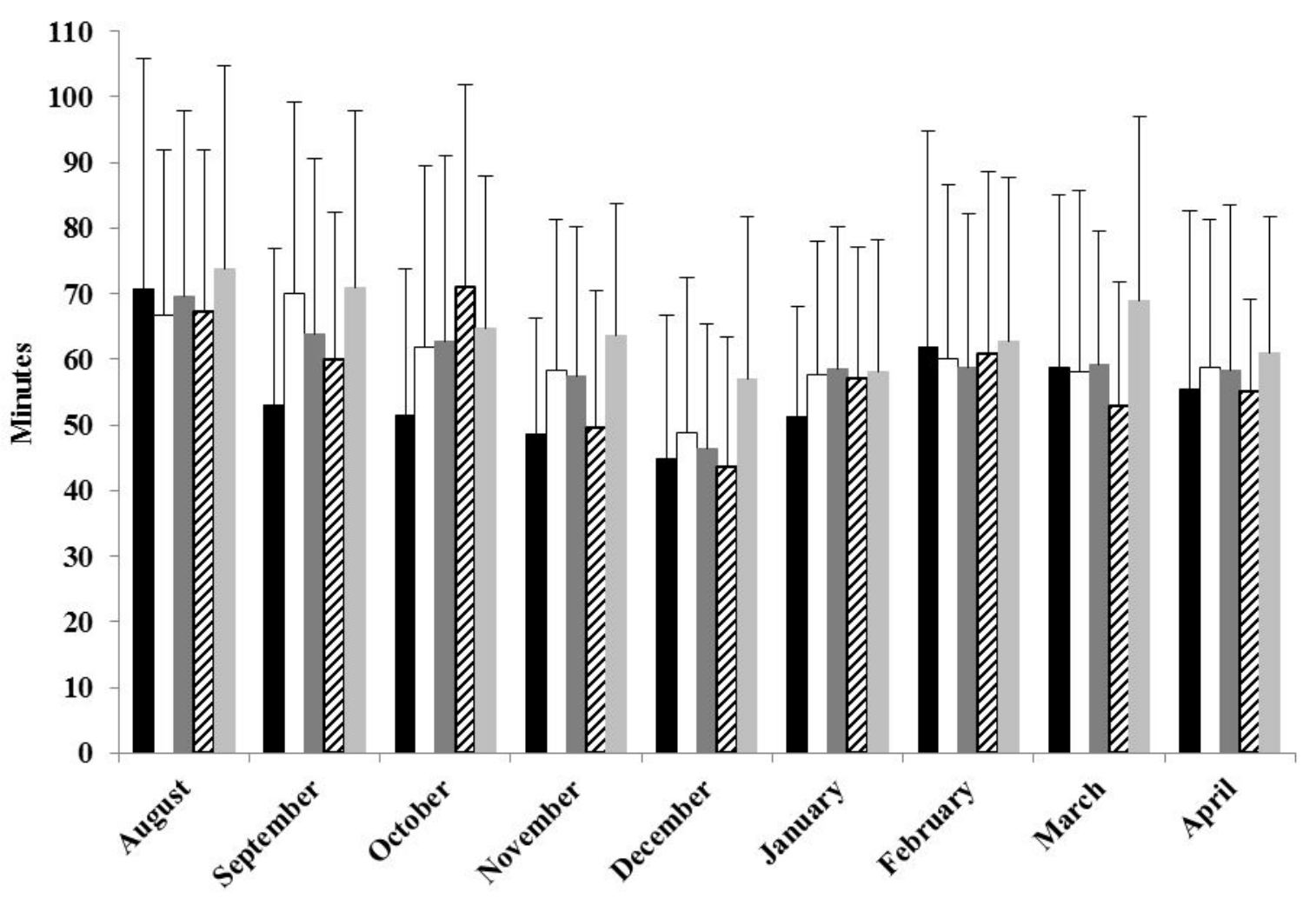

Figure 3. Mean \pm SD training session duration by playing position during the 2012-13 season (central defender $[\mathrm{CD}]$; wide defender [WD]; central midfielder [CM]; wide midfielder [WM]; attacker [A]). 


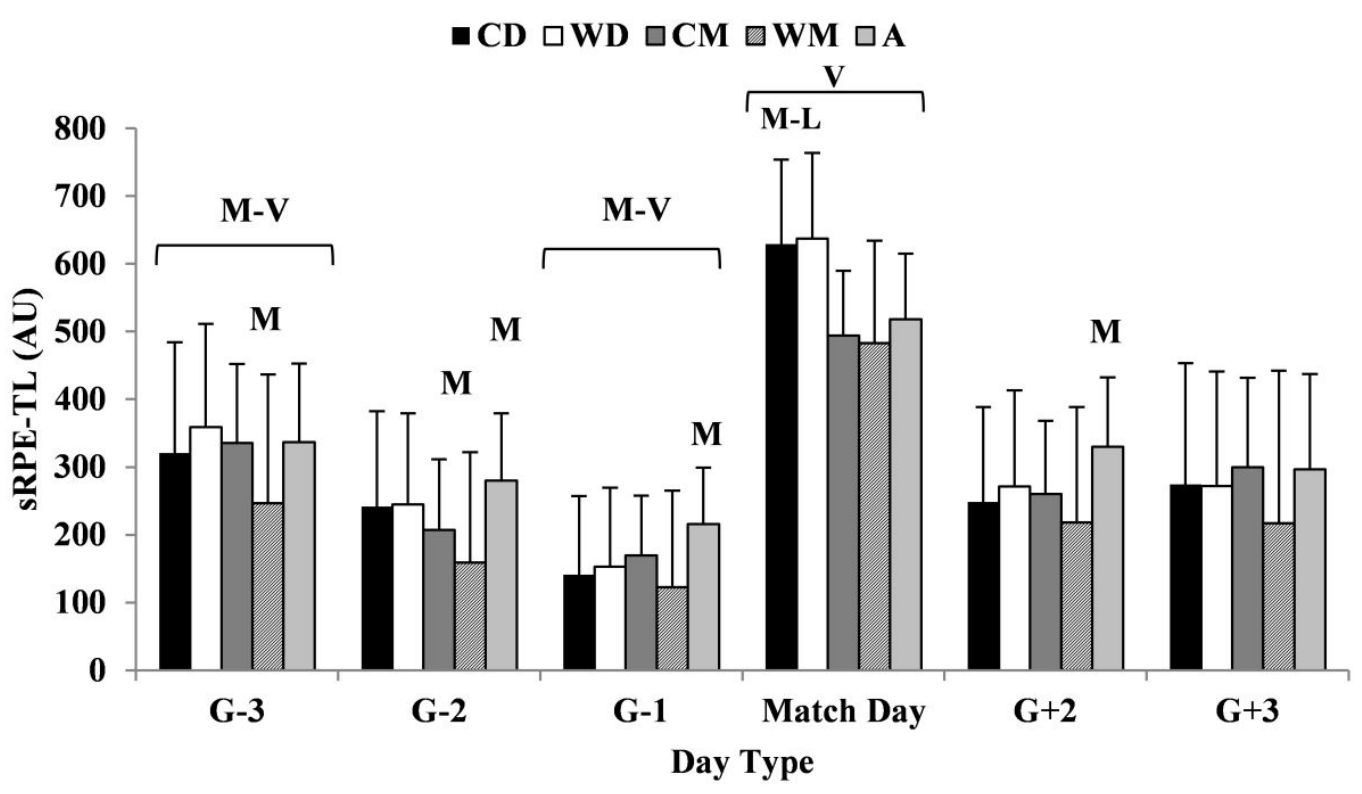

Figure 4. Mean \pm SD sRPE-TL for training day's pre- and post-competitive match and match-day between positions. Subscripts denote moderate (M), large (L), and very large (V). Day Type: G-3; L vs. G-2, V vs. G-1, M vs. G+2 and G+3. G-1; V vs. G-3, M vs. G-2, L vs. G+2, and G+3. MD; V vs. G-3, G-2, G-1, G+2 and G+3. Day Type x Playing Position: G-3; WM, M vs. WD. G-2; A, M vs. WM and CM. G-1; A, M vs. CD, WD, and WM. MD; CD, L vs. CM, M vs. WM and A. WD, L vs. CM, M vs. WM and A. G+2; A, M vs. CD, CM, and WM. 


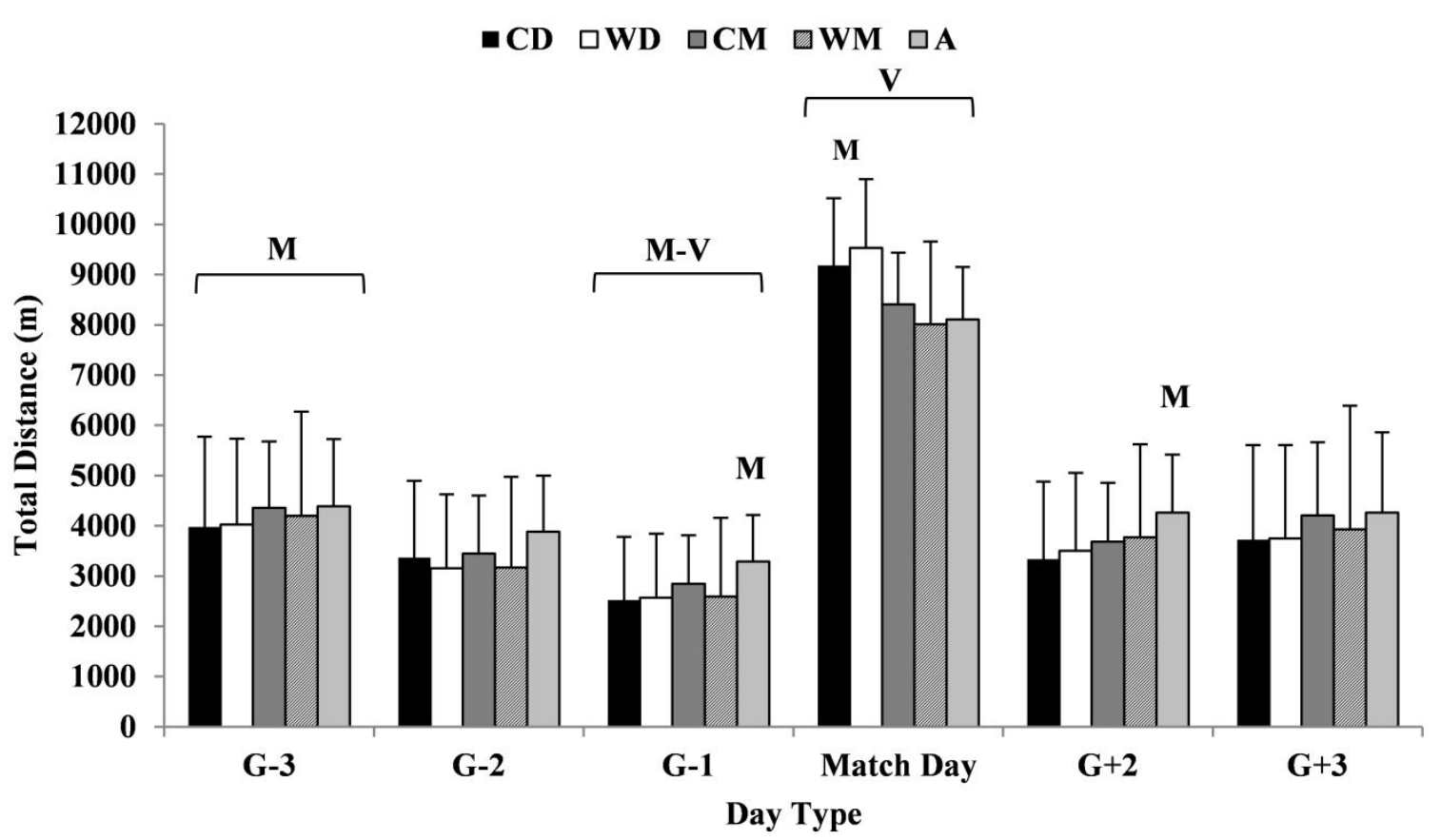

Figure 5. Mean \pm SD total distance for training day's pre- and post-competitive match and match day between positions. Subscripts denote moderate (M), large (L), and very large (V). Day Type: G-3; M vs. G-2 and G+2. G-1; V vs. G-3, M vs. G-2, L vs. G+2 and G+3. MD; V vs. G-3, G-2, G-1, G+2, and G+3. Day Type x Playing Position: G-1; A, M vs. CD and WD. MD; CD, M vs. CM, WM, and A. WD, M vs. CM, WM, and A. G+2; A, M vs. CD. 


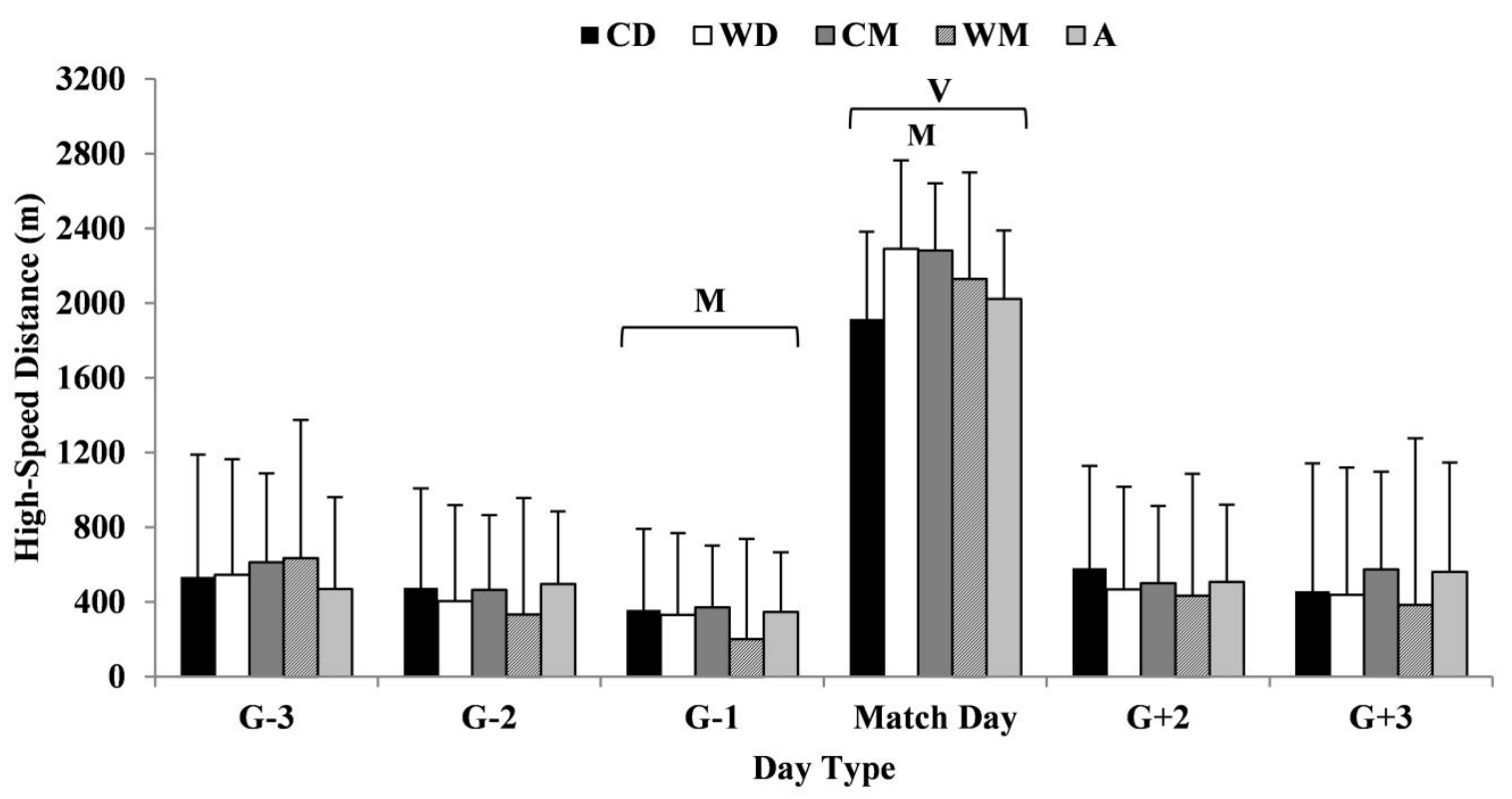

Figure 6. Mean \pm SD total high-speed distance for training day's pre- and post-competitive match and match day between positions. Subscripts denote (M), large (L), and very large (V).

Day Type: G-1; M vs. G-3, G+2 and G+3. MD; V vs. G-3, G-2, G-1, G+2, and G+3. Day Type x Playing Position: MD; WD, M vs. CD and A. CM, M vs. CD and A. 


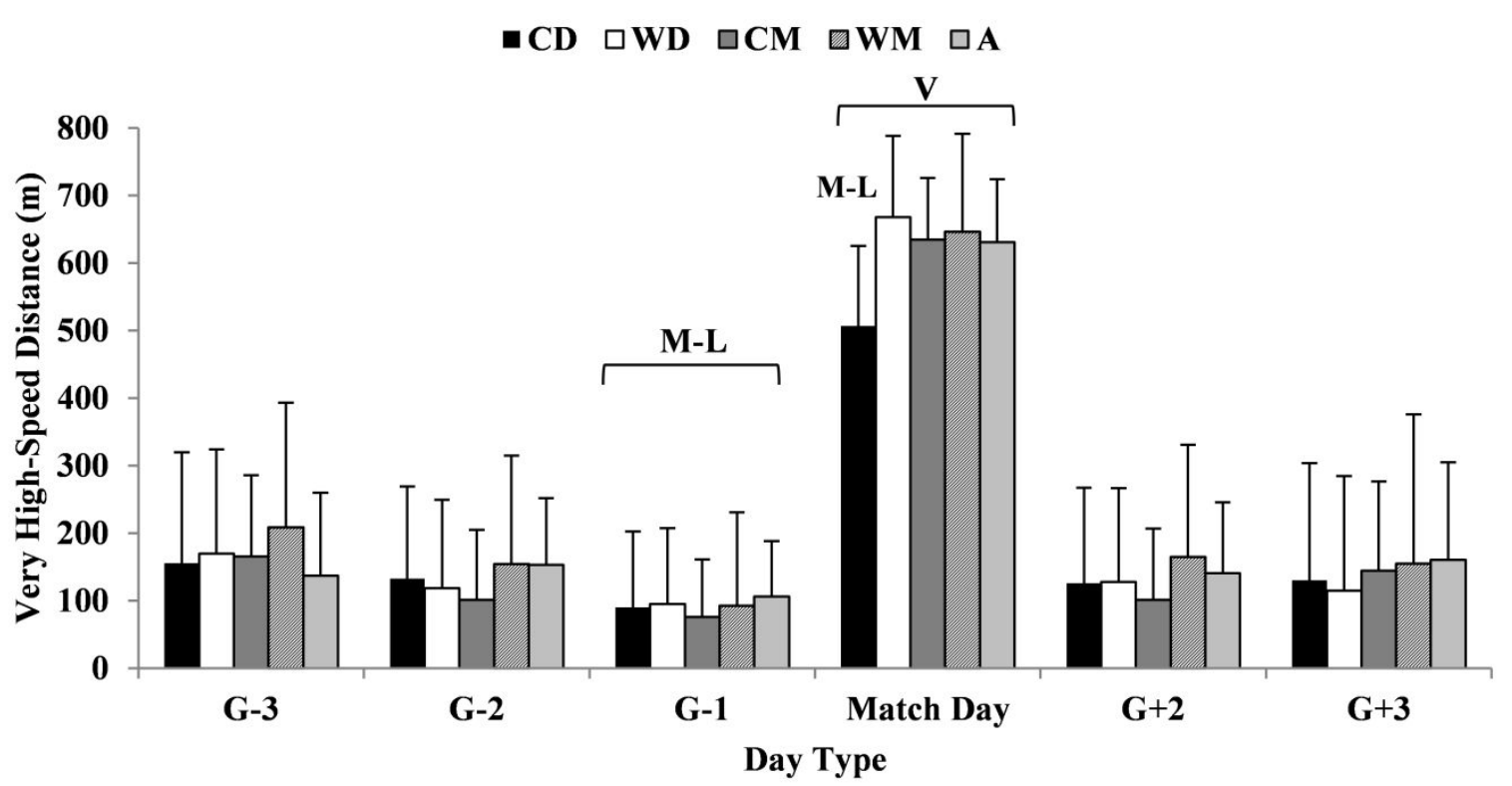

Figure 7. Mean \pm SD total very high-speed distance for training day's pre- and postcompetitive match and match day between positions. Subscripts denote moderate (M), large (L), and very large (V). Day Type: G-1; L vs. G-3, M vs. G-2, G+2, and G+3. MD; V vs. G-3, G-2, G-1, G+2, and G+3. Day Type x Playing Position: MD; CD, L vs. WD and CM, M vs. WM and A. 